\title{
Research and Practice of College Students' Cooperative Innovation Ability Training Mode under the "Internet +" Environment
}

\author{
Peipei Wang \\ Hankou University, Hubei 430212, China
}

Keywords: "Internet +" environment; college students; cooperative innovation ability; training mode

\begin{abstract}
In recent years, with the development of modern information technology, human beings have entered the age of the Internet. Network technology has been widely popularized and applied, which has brought great changes to people's life and work. Under the "Internet +" environment, the collaborative innovation ability of college students has prominent advantages, such as developing new entrepreneurial resources and changing traditional entrepreneurial thinking mode, and can effectively promote the achievement transformation of college students' innovative and entrepreneurial projects, so more and more attention has been paid to them. This paper will take the cooperative innovation ability of college students as the breakthrough point to explore the training mode of collaborative innovation ability of college students under the "Internet +" environment.
\end{abstract}

\section{Introduction}

The idea of "Internet +" was put forward by Prime Minister Li Keqiang in 2015 to get the wide recognition and positive response from all walks of life. Under the background of "Internet +", the cooperative innovation ability of college students has great potential to promote talent innovation ability, and universities are the important base of talent training in China. Therefore, it is of great practical significance for college students to cultivate cooperative innovation ability under the environment of "Internet +".

\section{Collaborative Innovation and Collaborative Innovation Ability of College students.}

In the 70s of last century, the idea of collaborative innovation began to emerge. It originated from the cooperation theory in the field of international innovation research. It was based on the mutual connection and coordination among the various innovative subjects to achieve the promotion of innovation ability and the development of innovation activities. The time developed to the twenty-first Century. In 2003, the concept of "open innovation" was put forward by the American scholar Chesbrough. This idea is mainly based on the integration of the internal and external innovation elements of the enterprise, and puts forward that enterprises should attach importance to building an open innovation model in the context of the increasingly frequent flow of modern talents. And relying on higher education resources such as universities to further enhance the ability of innovation, after that, the idea of collaborative innovation has gradually matured. In particular, collaborative innovation has the following characteristics: (1) each subject has a consistent goal and effective communication mechanism; and each participant can realize information sharing and resource sharing, and achieve multi-directional and multi-level communication and cooperation. Before the formation of collaborative innovation ideas, the innovation model has a strong linear and chain development characteristics, but with the growing maturity of the collaborative innovation thought, the traditional innovation model has been gradually replaced, forming a nonlinear, open and multi role model of innovation.

At present, our country is building an innovative country. We must realize the importance of collaborative innovation in enhancing our innovation capability. College students are the builders and developers of the country's future. Therefore, we must focus on improving the cooperative innovation ability of college students and establish a scientific and reasonable training mode of 
cooperative innovation ability, and strive to cultivate modern talents which meet the social development of our country and have strong innovation consciousness and innovation ability in the greatest degree. It should be clear that thought is the guide of action. Only by ensuring the correctness of the field of Ideological and political consciousness can we guarantee the development of the state of affairs in the right direction. Therefore, in order to effectively improve the cooperative innovation ability of college students, the students should first have the idea of synergistic innovation, and under the guidance of this thought, they should have their own. The role should be accurately positioned, focusing on cultivating the ability of interaction and coordination.

To some extent, "College Students' cooperative innovation ability" and "College Students' innovation ability" have some commonalities. For example, the two all require college students to have innovative consciousness and innovative ability. However, the two also have great differences. As for the "cooperative innovation ability of college students", it is more focused on college students. The ability of collaborative innovation, role positioning, coordination and communication should be cultivated.

\section{The Training Mode and Practice of College Students' Cooperative Innovation Ability under the "Internet +" Environment}

The cultivation of cooperative innovation ability of college students must be based on the establishment of a scientific and rational mode of collaborative innovation training, which is the prerequisite and foundation for the effective training of College Students' ability to cooperate with innovation. The establishment of cooperative innovation training mode is inseparable from the participation and support of the three main bodies of universities, governments and enterprises. To give full play to the prominent advantages of the three parties, the scientific and rational allocation of resources and the establishment of a communication and sharing platform to achieve the organic combination of industrial innovation, innovation and product innovation to the maximum extent. Combined with depth. Under the joint participation of universities, government and enterprises, the cooperative innovation ability of college students can provide the goal of providing quality innovation and entrepreneurial environment for college students, and the establishment and introduction of government departments, enterprise units and other related assisting and helping policies, and the synergy of college students to create new ability will be greatly improved.

At present, human beings have entered the era of "Internet +". Colleges and universities should follow the pace of the times to establish "Internet + education" training mode, actively carry out innovative and entrepreneurial education in the daily teaching activities, to ensure that the innovative and entrepreneurial education system can be developed in the direction of universality, specialization and operation. Under the environment of "networking +", efforts should be made to cultivate college students' sense of innovation, entrepreneurship and innovation. In particular, colleges and universities should attach importance to the instillation of collaborative innovation consciousness and the training of cooperative innovation ability in the daily course education. On the basis of this, the foundation of the cooperative innovation ability of college students should be consolidated and consolidated through the practice term, discipline competition and professional training. In addition, in order to effectively improve the effectiveness of College Students' collaborative innovation ability training, colleges and universities should realize the importance of inviting enterprise mentors into the classroom and carrying out special lectures on enterprise personages, and further strengthening the connection between the input of the concept of collaborative innovation of school and the energy requirements of enterprise innovation and entrepreneurship.

Students are only in theoretical contact with the sense of synergy in the school, but how the cooperative innovation ability needs to be further proved and perfected through practice. In order to effectively enhance the collaborative innovation ability of college students, we can provide students with practical and internship opportunities through school enterprise cooperation to ensure that the collaborative innovation content it has learned in the classroom can be used in practice. In practice, we can constantly test and improve their cooperative creative ability. In particular, the three main 
bodies of universities, governments and enterprises should set up innovative entrepreneurial incubators on the basis of scientific integration of internal and external resources, build up information sharing platform and resource sharing platform for collaborative innovation, and help and guide college students in funds, places and ideas. In the "Internet +" environment, colleges and universities should make full use of the advantages and resources of the Internet age, and build a platform for developing collaborative innovation ability, which is the main feature of information resources and team integration. The government departments should introduce relevant policies to encourage the major entrepreneurship parks to attract college students' projects, and give policy support and preferential treatment to college students in many aspects. In the enterprise, we can provide innovative and entrepreneurial practice base for college students through school enterprise cooperation, and promote the cooperative innovation ability of College Students under the joint leadership of university teachers and enterprises.

In order to effectively enhance the cooperative innovation ability of college students, it is necessary to make clear the important significance of giving full play to the advantages of network resources in the "Internet + " era to promote information sharing and resource integration. Only in this way can the information and resources of universities, governments and enterprises be used to achieve the greatest utilization and the most widely shared, for college students. Provide sufficient impetus for the cultivation and improvement of collaborative innovation capability. The establishment of the "Internet +" innovation and entrepreneurship information platform should be guided by the government, and the comprehensive utilization of modern information technology, such as Internet, large data and cloud computing in the era of "Internet +", should be supported by the government and the important assistance of universities and enterprises to provide technical support for students' innovation and entrepreneurship. As for the integration of various resources, it mainly includes the following contents. (1) educational resources in Colleges and universities. University education resources are the initial resources for college students to contact and learn the ideas of collaborative innovation. It has a basic and pilot role for the training of College Students' cooperative innovation ability. Therefore, colleges and universities should optimize the integration of curriculum resources, professional teacher resources and project resources. (2) government resources. The government has a strong social service ability, and has a strong policy support role in the training of College Students' ability to cooperate with innovation. Government departments can integrate information resources, capital resources and policy resources to provide a favorable social environment for the actual development of College Students' innovative projects. (3) enterprise resources. The enterprise is the experimental site and testing place for the cooperative innovation ability of college students. It can give guidance to the college students' ability to cooperate with innovation and the quality of practice. Therefore, it is necessary to integrate the technical resources of the enterprises, expert resources and enterprise tutor resources to improve the cooperative innovation ability of college students.

First of all, the strategic coordination guarantee. From the point of view of the government, we should do a good job of top level design, stand on the strategic height to grasp the overall situation of the training mode of College Students' synergistic innovation ability, and strive to achieve the goal of the traditional industry and the scientific and technological development of the new industry to the greatest extent, and give full play to the guiding role of the government in the new venture of college students and the creation of college students. The role of the transformation of the industry project. From the point of view of enterprise, enterprises should be based on the actual situation of their own development, strengthen scientific and technological innovation and institutional innovation, so as to provide a good platform for the development and promotion of collaborative innovation practice for college students. In addition, enterprises should further analyze and study the relevant policies promulgated by the government on the training mode of university students' collaborative innovation ability, and actively respond to the government's call. In the end, from the point of view of the University, it is necessary to combine the formulation of talent training mode with the actual demand of national talents, in order to continuously improve the quality of the national strategic innovation industry, to formulate the training mechanism for the cooperative 
innovation ability of college students, introduce high-level talents, add subject construction, and continue to be in the teaching field. Innovation in the academic field.

Secondly, the protection of intellectual property rights and the distribution of interests. In the initial stage, the cultivation of College Students' innovative ability should be based on the actual situation of each participating entity to make the management of intellectual property rights and the formulation of the mechanism of interest distribution. In particular, we should rationally divide the share of technical results with their respective input or investment proportion, and fix them in the form of standardized and institutionalized provisions to ensure the development of innovative and entrepreneurial projects for college students. In addition, it is necessary to make clear the relationship between the interests and obligations among the various subjects, and the relationship between pay and income, so as to ensure the equivalence and balance of the acquisition of risk and interest to promote the formation of the incentive mechanism.

Finally, the fund guarantee mechanism. (1) take a variety of measures to broaden the financing channels to provide adequate financial support for the development of innovative and entrepreneurial projects for college students, and to promote the transformation of the results of collaborative innovation ability of college students. (2) setting up a cooperative innovation practice education fund for college students, which will be commended and encouraged by the units and individuals who have had outstanding contributions in the process of Cultivating College Students' cooperative innovation ability, and provide financial support for the college students' innovative and entrepreneurial projects.

(1) Building an innovative platform

Under the "Internet +" environment, the cooperative innovation ability of college students has been greatly improved. Relying on the large Internet enterprises, the innovative platform has been built in a timely and effective way, which makes the students' ability to cooperate and innovation in place. The large Internet enterprise has rich information resources and technical resources. It can provide good information support and technical support for the collaborative innovation project of College Students under the advantages of strong R \& D ability, innovation ability and management ability. The construction of the innovative platform maximizes the resources advantage of the three people of the government, universities and enterprises. The R \& D team and the business operation mode are beneficial to provide solid foundation and strong guarantee for the training and practice of collaborative innovation ability of college students.

(2) Opening up space to create space

In order to further encourage college students to improve their collaborative innovation ability under the "Internet +" environment, the creation of space has been effectively established. The public creation space has the advantages of human resources, material resources, and the obvious characteristics of the advantages of technical resources. It can provide strong talent, material and technical support for the cultivation of collaborative innovation ability of college students. Under the "Internet +" environment, college students' innovative and entrepreneurial projects can mobilize the beneficial resources of the whole society to continuously improve their operability and actual competitiveness, so that the entrepreneurs can gain higher benefits at a lower cost and give full play to the effective support for the new venture projects of college students. Universities, governments and enterprises are the main participants in the construction of the training mode of university students' collaborative innovation ability. The university is the main position to cultivate the innovative ability of the college students, and the source of the university students to acquire the knowledge and skills of innovation and entrepreneurship. The government is the writer of the preferential policies and assisting policies of the college students' innovation and entrepreneurship project, and has the ability to coordinate the financial institutions, tax institutions and scientific and technological institutions to help college students to innovate and start a pioneering project. Industry is the main body of the collaborative innovation ability of university students. Under the guidance of enterprises, college students can consolidate their own ability of collaborative innovation. And the development of public space is concentrated on the three aspects of the strength of universities, government and enterprises. In the case of the full convergence of the advantages of 
all parties, the cooperative innovation ability of college students will be further promoted.

\section{Conclusion}

Based on the training mode of collaborative innovation ability of College Students under the "Internet +" environment, this paper analyzes the training mode of the cooperative innovation ability of College Students under the "Internet +" environment, for example, to build a "Trinity" training model for innovative and entrepreneurial talents and to build up a business incubating enterprise with the Internet as the main platform. On the basis of this, the practice of cultivating the cooperative innovation ability of College Students under the "Internet + " environment is discussed on the basis of two aspects of building an innovative platform and opening up the space. The hope is of some reference for the optimization and upgrading of the training mode of the collaborative innovation ability of College Students under the "Internet +" environment.

\section{References}

[1] Wang Y, Chen S J. The Mode Study of College Students' Entrepreneurship Education and Ideological Education [J]. Yinshan Academic Journal, 2016.

[2] Qiang-Qiang W U, Kou W J, Shen L, et al. Exploration of engineering training on college students' practical innovation ability[J]. Laboratory Science, 2017.

[3] Yang Z Y. The Research and Practice of the Construction about the Training System of Innovation Ability in Vocational College [J]. Journal of Henan Mechanical \& Electrical Engineering College, 2017.

[4] Zhang K L. Research on the Improvement of College Students' Innovation and Entrepreneurship Ability Cultivated by Craftsman's Spirit [J]. Theory \& Practice of Education, 2017.

[5] Weng R, Liu X, Lin X, et al. Research on the Training Mode of Application-oriented Talents of Environmental Engineering [J]. Journal of Wuyi University, 2017.

[6] Wang L Y. Research and practice of training mode of master of engineering in architectural specialty [J]. Journal of Changchun Institute of Technology, 2017. 